\title{
OA05-03. Efficacy study of a T-cell-based DNA vaccine delivered by intradermal electrotransfer in macaques
}

N Dereuddre-Bosquet ${ }^{1,4}$, M Baron ${ }^{4}$, I Méderlé-Mangeot ${ }^{4}$, K Kaldma ${ }^{2}$, R Sikut ${ }^{2}$, A Männik² I Stanescu² ${ }^{2}$ M Ustav³ ${ }^{3}$ R Le Grand ${ }^{4}$ and F Martinon*4

\author{
Address: ${ }^{1}$ FIT Biotech, Tartu, Estonia, ${ }^{2}$ FIT Biotech Oyj Plc, Tampere, Finland, ${ }^{3}$ Institute of Technology, University of Tartu, Tartu, Estonia and \\ ${ }^{4}$ Institute for Emerging Diseases and Innovative Therapies, DSV, CEA/Division of Immuno-Virology, Fontenay aux Roses, France \\ * Corresponding author
}

from AIDS Vaccine 2009

Paris, France. 19-22 October 2009

Published: 22 October 2009

Retrovirology 2009, 6(Suppl 3):O33 doi:10.1 I86/I742-4690-6-S3-O33

This abstract is available from: http://www.retrovirology.com/content/6/S3/O33

(c) 2009 Dereuddre-Bosquet et al; licensee BioMed Central Ltd.

\section{Background}

We recently demonstrated that intradermal (ID) injection with electropororation (EP) of a new HIV DNA vaccine induced strong and persistent specific T-cells in macaques. Here, we used an equivalent vaccine encoding SIVmac251 antigens in order to study its efficacy in SIV mucosal challenge of macaques.

\section{Methods}

Eighteen macaques were vaccinated with $1 \mathrm{mg}$ of the auxo-GTU-MultiSIV DNA at week 0, 4 and 12: either by the ID route only $(n=6)$, or by the ID route combined with EP (ID+EP; $\mathrm{n}=6)$ or ID+EP with co-injection of a plasmid used as "genetic-adjuvant" $(\mathrm{n}=6)$. A control group of unvaccinated animal was included $(n=6)$.

\section{Results}

Before challenge, all animals raised SIV-specific T-cells as evidenced by IFN- $\gamma$ ELISPOT $(110 \pm 42,921 \pm 310$ and $905 \pm 252$ spots/106 cells in the ID only, ID+EP and ID+EP+genetic-adjuvant groups, respectively). Weak and transient antibody responses were detected. All animals were intrarectally challenged with pathogenic SIVmac251. T-cell responses increased in both ID+EP groups as early as week 1 post-challenge $(3,898 \pm 395$ and 3,031 \pm 893 spots, respectively), and up to 12,000 spots by week 2 . Macaques immunized ID only raised delayed and lower responses remaining earlier and higher than in controls. At peak of viremia, plasma viral load was significantly reduced $(\mathrm{p}=0.0104)$ in the ID+EP group. Interestingly, no reduction of plasma viral load was observed by that time in the genetic-adjuvant group despite high anamnestic responses. Differences in anti-Gag responses may explain this observation. Viremia was not reduced in the ID only group. At set-point, although similar plasma viral load in all groups, reduction of SIV-DNA copies in rectal biopsies was observed in the vaccinated animals.

\section{Conclusion}

Electroporation results induced high anamnestic T-cells responses which are better associated with the control of early plasma viremia. Impact of vaccine on disease progression is currently under evaluation. 